\title{
Laser-modified titanium surfaces enhance the osteogenic differentiation of human mesenchymal stem cells
}

Tatiana A. B. Bressel ${ }^{1 \dagger}$, Jana Dara Freires de Queiroz ${ }^{1,3 \dagger}$, Susana Margarida Gomes Moreira', Jéssyca T. da Fonseca?, Edson A. Filho², Antônio Carlos Guastaldi ${ }^{2}$ and Silvia Regina Batistuzzo de Medeiros ${ }^{1 *}$

\begin{abstract}
Background: Titanium surfaces have been modified by various approaches with the aim of improving the stimulation of osseointegration. Laser beam (Yb-YAG) treatment is a controllable and flexible approach to modifying surfaces. It creates a complex surface topography with micro and nano-scaled patterns, and an oxide layer that can improve the osseointegration of implants, increasing their usefulness as bone implant materials.

Methods: Laser beam irradiation at various fluences $\left(132,210\right.$, or $\left.235 \mathrm{~J} / \mathrm{cm}^{2}\right)$ was used to treat commercially pure titanium discs to create complex surface topographies. The titanium discs were investigated by scanning electron microscopy, X-ray diffraction, and measurement of contact angles. The surface generated at a fluence of $235 \mathrm{~J} / \mathrm{cm}^{2}$ was used in the biological assays. The behavior of mesenchymal stem cells from an umbilical cord vein was evaluated using a 3-(4,5-dimethylthiazol-2-yl)-2,5-diphenyltetrazolium bromide (MTT) assay, a mineralization assay, and an alkaline phosphatase activity assay and by carrying out a quantitative real-time polymerase chain reaction for osteogenic markers. CHO-k1 cells were also exposed to titanium discs in the MTT assay.

Results: The best titanium surface was that produced by laser beam irradiation at $235 \mathrm{~J} / \mathrm{cm}^{2}$ fluence. Cell proliferation analysis revealed that the $\mathrm{CHO}-\mathrm{k} 1$ and mesenchymal stem cells behaved differently. The laser-processed titanium surface increased the proliferation of $\mathrm{CHO}-\mathrm{k} 1$ cells, reduced the proliferation of mesenchymal stem cells, upregulated the expression of the osteogenic markers, and enhanced alkaline phosphatase activity.

Conclusions: The laser-treated titanium surface modulated cellular behavior depending on the cell type, and stimulated osteogenic differentiation. This evidence supports the potential use of laser-processed titanium surfaces as bone implant materials, and their use in regenerative medicine could promote better outcomes.
\end{abstract}

Keywords: Titanium, Laser beam (Yb-YAG), Surface modification, Human umbilical cord, Mesenchymal stem cells, Osteoinduction, Biocompatibility

\section{Background}

In recent decades, research into biomaterials has increased, in part to meet demands for materials that will extend the longevity of an ageing population [1]. Concerning the applications of regenerative medicine, a synthetic scaffold should not only be biocompatible and biodegradable to allow native tissue integration, but should also

\footnotetext{
*Correspondence: sbatistu@gmail.com; sbatistu@cb.ufrn.br

${ }^{\dagger}$ Equal contributors

${ }^{1}$ Departamento de Biologia Celular e Genética, CB-UFRN, Universidade Federal do Rio Grande do Norte, Campus Universitário, Lagoa Nova, 59072-970 Natal, RN, Brazil

Full list of author information is available at the end of the article
}

mimic the hierarchical structure of the native tissue. The extracellular matrix is the natural cell scaffold, and it has a wide variety of topographies at the micro/nano scale [2].

Although diverse implantable biomaterials can be used in bone regenerative medicine [3], titanium (Ti) has long been the gold standard for orthopedic and dental approaches [4]. However, several problems related to a loss of aseptic character and implant failure have been described [5]. Furthermore, several critical parameters, such as interactions with body fluids and the physicochemical properties of the implants, are crucial for the longevity and load-bearing capacity of the materials [6]. 
Cell attachment and cell growth are primarily associated with the chemistry of the material and surface characteristics such as roughness, wettability, and surface energy [7].

Titanium surfaces have been modified by various approaches with the aim of improving the stimulation of osseointegration. Laser beam (Yb-YAG) treatment is a controllable and flexible approach to modifying surfaces, and it can be used in industrial applications $[4,8]$. The technique produces a surface with nano-to-micro hybrid structures, high purity, increased surface area, corrosion resistance, biocompatibility owing to the formation of oxide layers, and an increase in bone-implant interactions $[8,9]$. The laser irradiation parameters influence surface melting; therefore, it is possible to create different surfaces by simply changing those parameters [8]. It is theoretically possible to develop a surface with characteristics optimized for cell attachment, growth, and/or differentiation.

Human mesenchymal stem cells (hMSCs) have been utilized in numerous studies, including those on bone repair, because they play a crucial role in bone regeneration and fixation $[3,5,10,11]$. Human bone marrow mesenchymal stem cells (hBM-MSCs) are the most commonly used cells. However, their isolation can be invasive, and their ability to differentiate decreases with age $[2,12,13]$. Neonatal tissues, such as those found in the umbilical cord, are an easily accessible source of hMSCs, and they can be obtained without resorting to painful or invasive techniques. Moreover, they are available in relatively large quantities. It is possible that the hMSCs from umbilical cord tissue are at an earlier stage than cells from adult bone marrow [12]; they therefore have lower immunogenicity, an enhanced proliferation rate, and a greater lifespan $[2,12,13]$.

Hybrid hMSC-biomaterial scaffolds therefore have potential for use in bone prosthetics. In situ, cells migrate off the scaffold and undergo differentiation leading to integration of the device and regeneration of the damaged tissue. Furthermore, factors such as the physical properties of the scaffold can stimulate and improve this process [2].

Based on a hybrid hMSC-biomaterial approach, the aim of the present study was to investigate the osteoregenerative effect of a laser-modified nano-to-micro-scale hybrid surface on human umbilical cord mesenchymal stem cells (hUC-MSCs).

\section{Methods}

\section{Titanium discs}

The Ti discs were prepared at UNESP (Araraquara, Brazil). Commercially pure grade II Ti discs (diameter $=15 \mathrm{~mm}$; thickness $=2 \mathrm{~mm}$ ) were subjected to multipulse Yb:YAG laser irradiation treatment using an OmniMark machine (Omnitek Tecnologia). The Ti discs were polished with abrasive grit (grades 240-600), then treated with laser radiation at various fluences $\left(132,210\right.$, or $\left.235 \mathrm{~J} / \mathrm{cm}^{2}\right)$. According to the characterization results, the laser-processed titanium (LPT) surface obtained at $235 \mathrm{~J} / \mathrm{cm}^{2}$ fluence was selected for the biological assays. Untreated Ti discs were used as controls. All of the discs were cleaned and sterilized with gamma radiation.

\section{Sample characterization}

The surface topographies of the Ti discs were investigated by scanning electron microscopy (SEM) (JSM T330A scanning microscope). The crystalline composition of the modified surfaces, such as the types and phases of oxides formed, were analyzed by X-ray diffraction (XRD) using a SIEMENS D5000 X-ray diffractometer (Siemens, Munich, Germany), with angular scanning between 10 and $80^{\circ}$.

The oxide layers were characterized by comparing the obtained data with the standard records in the Committee for Powder Diffraction Studies (CPDS) database. Quantitative phase analysis was carried out using Rietveld refinements [14]. The phases considered are presented in Table 1 . The wettability of the samples was evaluated by measuring the contact angle $(\Theta)$ at room temperature (sessile drop method) using an OCA Contact Angle System (OCA-15 video-based optical contact angle meter). The sessile drop method was applied with ultrapure water and the contact angle was calculated by the LaplaceYoung function (SCA 20 software; Dataphysics Instruments GmBh. Germany). The measurement was repeated three times for each sample to obtain the mean value of the contact angle $(\Theta)$ for the various surfaces (Table 2).

\section{Cell culture}

Human umbilical cord mesenchymal stem cells (hUCMSCs) were isolated, characterized, and cultured as described previously [15], and following the Local Ethics Committee directions (FR132464). A Chinese hamster ovary cell line $\left(\mathrm{CHO}-\mathrm{k} 1, \mathrm{ATCC}^{\circ} \mathrm{CCL}-61^{\mathrm{m}}\right)$, kindly provided by Dr Carlos Menck, was cultured as described by de Queiroz et al. [16].

Table 1 Crystalline structures of identified phases obtained by laser ablation and percentage of oxide layer in the irradiated titanium surfaces

\begin{tabular}{llcc}
\hline Phase & Oxide layer (\%) & & \\
\cline { 3 - 4 } & $132 \mathrm{~J} / \mathrm{cm}^{2}$ & $210 \mathrm{~J} / \mathrm{cm}^{2}$ & $235 \mathrm{~J} / \mathrm{cm}^{2}$ \\
\hline a titanium (hexagonal) & 47.1 & 42.2 & 43.5 \\
$\beta$ titanium (cubic) & 11.2 & 9.4 & 5.9 \\
$\mathrm{TiO}$ (rhombohedral) & 5.3 & 6.4 & 11.4 \\
$\mathrm{Ti}{ }_{2} \mathrm{O}$ (rhombohedral) & 27.7 & 38.5 & 7.3 \\
$\mathrm{Ti}_{3} \mathrm{O}$ (rhombohedral) & - & 1.3 & 30.8 \\
$\mathrm{Ti}_{6} \mathrm{O}$ (rhombohedral) & 8.6 & 2.2 & 1.0 \\
\hline
\end{tabular}


Table 2 Contact angles measured on laser-ablated and titanium control surfaces

\begin{tabular}{lllll}
\hline Surface & 1st measurement & 2nd measurement & 3rd measurement & Mean \pm SD \\
\hline Titanium control & 68.5 & 65.2 & 54.8 & $62.83 \pm 7.15$ \\
$132 \mathrm{~J} / \mathrm{cm}^{2}$ & 0 & 0 & 0 & 0 \\
$210 \mathrm{~J} / \mathrm{cm}^{2}$ & 116.9 & 111.9 & 94.5 & $107.77 \pm 11.76$ \\
$235 \mathrm{~J} / \mathrm{cm}^{2}$ & 0 & 0 & 0 & 0 \\
\hline
\end{tabular}

SD standard deviation

The hUC-MSCs and CHO-k1 cells were seeded onto the Ti discs $\left(10^{4}\right.$ cells $\left./ \mathrm{cm}^{2}\right)$ in complete Dulbecco's modified Eagle's medium (DMEM) with high glucose content (DMEM supplemented with $10 \%$ fetal bovine serum, $2 \mathrm{mM}$ L-glutamine, $50 \mathrm{U} / \mathrm{ml}$ of penicillin, and 50 $\mu \mathrm{g} / \mathrm{ml}$ of streptomycin), and grown for $3 \mathrm{~h}, 1$ day, 3 days, and 7 days for adhesion and proliferation analysis by 3-(4,5-dimethylthiazol-2-yl)-2,5-diphenyltetrazolium bromide (MTT) assay (Molecular Probes $\left.{ }^{\mathrm{st}}\right)$, as described previously [16]. Briefly, both cell types were maintained at $37^{\circ} \mathrm{C}$ in $5 \% \mathrm{CO}_{2}$, and the medium was replaced every 3 days. After the exposure times, the medium was removed and a solution of $1 \mathrm{mg} / \mathrm{ml} \mathrm{MTT}$ was added allowing for $4 \mathrm{~h}$ of incubation. The solution was then aspirated and the insoluble formazan crystals were dissolved in $1 \mathrm{ml}$ of DMSO. The optical density was measured at $570 \mathrm{~nm}$. Data were presented as the mean of three independent experiments.

Extracellular mineralization and gene expression were investigated in hUC-MSCs seeded and cultured on the Ti discs for 7 and 14 days in the presence of osteogenic medium (OM). OM comprised complete DMEM supplemented with osteogenic inducers $\left(10^{-7} \mathrm{M}\right.$ dexamethasone, $10 \mathrm{mM}$ glycerophosphate, and $0.2 \mathrm{mM}$ ascorbic acid) (Sigma-Aldrich, St. Louis, MO, USA). We also investigated cells cultured in DMEM without osteogenic inducers as the basal medium (BM).

\section{Morphology analysis by SEM}

The adhesion and morphology of the hUC-MSCs and CHO-K1 cells on the LPT and Ti control surfaces were investigated by SEM after $24 \mathrm{~h}$ and 7 days. The samples were fixed with $2.5 \%$ glutaraldehyde, treated with $1 \%$ osmium tetroxide $\left(\mathrm{OsO}_{4}\right)$ for $30 \mathrm{~min}$, and dehydrated in a series of ethanol solutions (30, 50, 70, 90, and 100\%). The samples were visualized using a Quanta 200 SEM (FEI, OR, USA) after gold sputter coating.

\section{Evaluation of osteogenic differentiation}

Alkaline phosphatase (ALP) activity, extracellular matrix mineralization, and the expression of osteogenic gene markers were used to evaluate hUC-MSC differentiation.

\section{Alkaline phosphatase activity}

ALP activity was measured after 3 and 7 days using an alkaline phosphatase activity kit (Labtest Diagnostica
Ltda, Minas Gerais, Brazil), according to the manufacturer's instructions. Briefly, cells were incubated with 50 $\mu \mathrm{l}$ of substrate and $500 \mu \mathrm{l}$ of buffer for $30 \mathrm{~min}$. After this period, $1.5 \mathrm{ml}$ of color reagent was added and the ALP activity was measured at $590 \mathrm{~nm}$. The plate culture wells were then washed out with cold PBS and $500 \mu \mathrm{l}$ of Tris- $\mathrm{HCl}$ buffer was added in order to lyse cells and to determine the protein content, using a BCA kit (Bioagency Biotecnologia, São Paulo, Brazil). The measurement was repeated twice with technical triplicate to obtain the mean value and the standard deviation (SD).

\section{Extracellular matrix mineralization}

The cells were fixed with $70 \%$ cold ethanol for $1 \mathrm{~h}$, washed three times with distilled water, and stained with Alizarin Red S (40 mM, pH 4.1) at room temperature for $5 \mathrm{~min}$. The quantitative analysis was carried out as described by Jääger et al. [17]. This analysis was repeated three times.

Evaluation of gene expression by quantitative real-time PCR Total RNA was extracted with a PureLink ${ }^{\odot}$ RNA mini kit (Thermo Fisher Scientific) and reverse-transcribed using a High Capacity cDNA Reverse Transcription Kit (Qiagen) following the manufacturer's protocol. Three RNA samples were prepared for each test condition and repeated twice in an independent way. Real-time PCR was performed on a 7500 Fast Real-Time PCR system (Applied Biosystems). The samples were subjected to quantitative real-time polymerase chain reaction (qRT-PCR) using a panel of human osteogenic primers (Table 3). Differences

Table 3 Human gene primer sequences

\begin{tabular}{lll}
\hline Gene & Forward primer $\left(5^{\prime}-3^{\prime}\right)$ & Reverse primer $\left(5^{\prime}-3^{\prime}\right)$ \\
\hline GAPDH & AGGTGCGTGTGAACGGATTG & TGTAGACCATGTAGTTGAGTCA \\
RUNX2 & TCAACGATCTGAAGATTGGGGG & GGGGAGGATTTGGAAGACGG \\
BMP2 & TTCGGCCTGAAACAGAGACC & CCTGAGTGCCTGCGATACAG \\
ALPL & ACTGGTACTCAGACAACGAGAT & ACGTCAATGTCCCTGATGTTATG \\
OCN & GGCGCTACCTGTATCAATGG & GTGGTCAGCCAACTGGTCA \\
OPN & GAAGTTCGCAGACCTGACAT & GTATGCACCATTCAACTCCTCG \\
\hline
\end{tabular}

GAPDH glyceraldehyde-3-phosphate dehydrogenase, $R U N X 2$ runt-related transcription factor 2, BMP2 bone morphogenetic protein 2, ALPL alkaline phosphatase, $O C N$ osteocalcin, OPN osteopontin 
in gene expression on the LPT were evaluated by the $\Delta \Delta \mathrm{Ct}$ method normalized to glyceraldehyde-3-phosphate dehydrogenase (GAPDH) expression, and reported as the fold change in relation to the Ti controls.

\section{Statistical analysis}

All tests were performed in at least two independent experiments with three technical replicates. The data were analyzed using one-way analysis of variance (ANOVA) $(p<0.05)$ and Tukey's test for multiple comparisons among groups. Data were expressed as the mean \pm SD.

\section{Results}

\section{Sample characterization}

The laser-treated $\mathrm{Ti}$ discs had a complex micro and nano-scaled topography with a typical porous structure and spherical particles (Fig. 1). The crystalline structure confirmed the formation of stoichiometric and nonstoichiometric oxides (Fig. 2). We observed the highest percentage of oxide formation (50.5\%) and complete wettability $(\Theta=0)$ on the LPT produced by irradiation at $235 \mathrm{~J} / \mathrm{cm}^{2}$ fluence (Table 1). Therefore, we selected that material for the subsequent evaluation of cellular behavior.

\section{Cell morphology and proliferation}

SEM revealed morphological differences in the cells after 1 day of growth on the Ti discs (Fig. 3). The CHO-K1 cells and hUC-MSCs cultured on the LPT surface were located mainly in the pores and gaps between the $\mathrm{Ti}$ particles (Fig. 3b, e). The cells were well spread, and displayed numerous filopodia (Fig. 3c, f). In contrast, the cells on the $\mathrm{Ti}$ controls were round (Fig. $3 \mathrm{a}, \mathrm{d}$ ). After 7 days, the Ti controls were uniformly covered with either type of cells (Fig. 4a, d), whereas cell behavior seemed to depend on cell lineage on the LPT surface (Fig. 4b, e).

The analysis of cell proliferation also revealed a difference between the behaviors of the CHO-k1 cells and the hUC-MSCs (Fig. 5). The LPT surface seems to have improved the proliferation of $\mathrm{CHO}-\mathrm{k} 1$ cells. The peak of proliferation occurred after 3 days (optical density $(\mathrm{OD})=3.700$ for $\mathrm{LPT}$ versus $\mathrm{OD}=2.345$ for the Ti control, $p<0.001)$. At 7 days, the rate of proliferation of $\mathrm{CHO}-\mathrm{k} 1$ cells decreased to levels similar to those found on the Ti control. SEM analysis revealed no alteration in cell growth between the LPT and the Ti control surface (Fig. 4d, e). On both Ti surfaces, numerous cells were observed distributed uniformly on the surface.

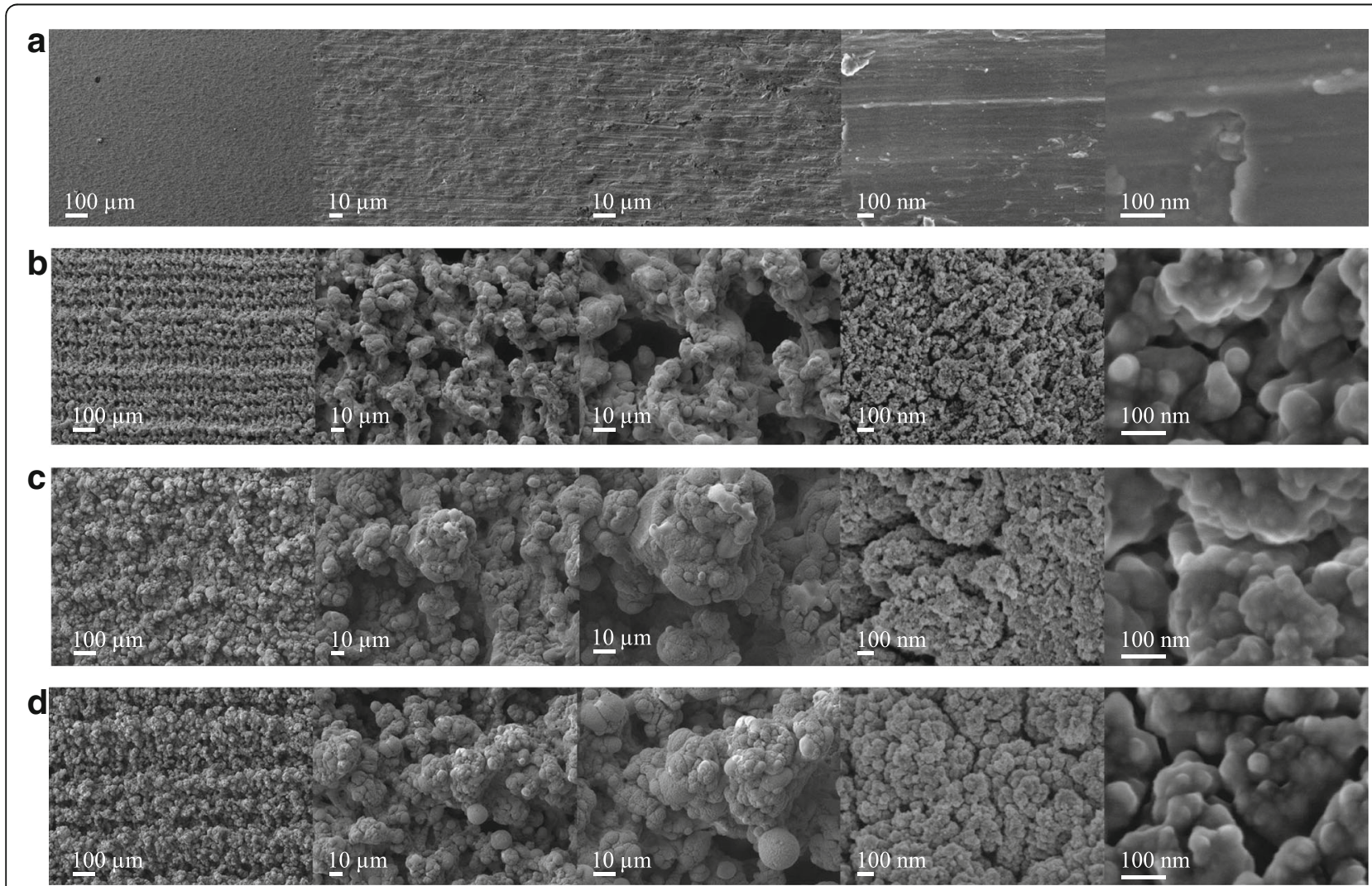

Fig. 1 Scanning electron microscopy images of Ti control (a), laser-processed titanium (LPT) produced using laser radiation at $132 \mathrm{~J} / \mathrm{cm}^{2}$ fluence (b), LPT produced using laser radiation at $210 \mathrm{~J} / \mathrm{cm}^{2}$ fluence (c), and LPT produced using laser radiation at $235 \mathrm{~J} / \mathrm{cm}^{2}$ fluence (d). Surfaces at $\times$ $100, \times 500, \times 1000, \times 50,000$, and $\times 200,000$ magnification 

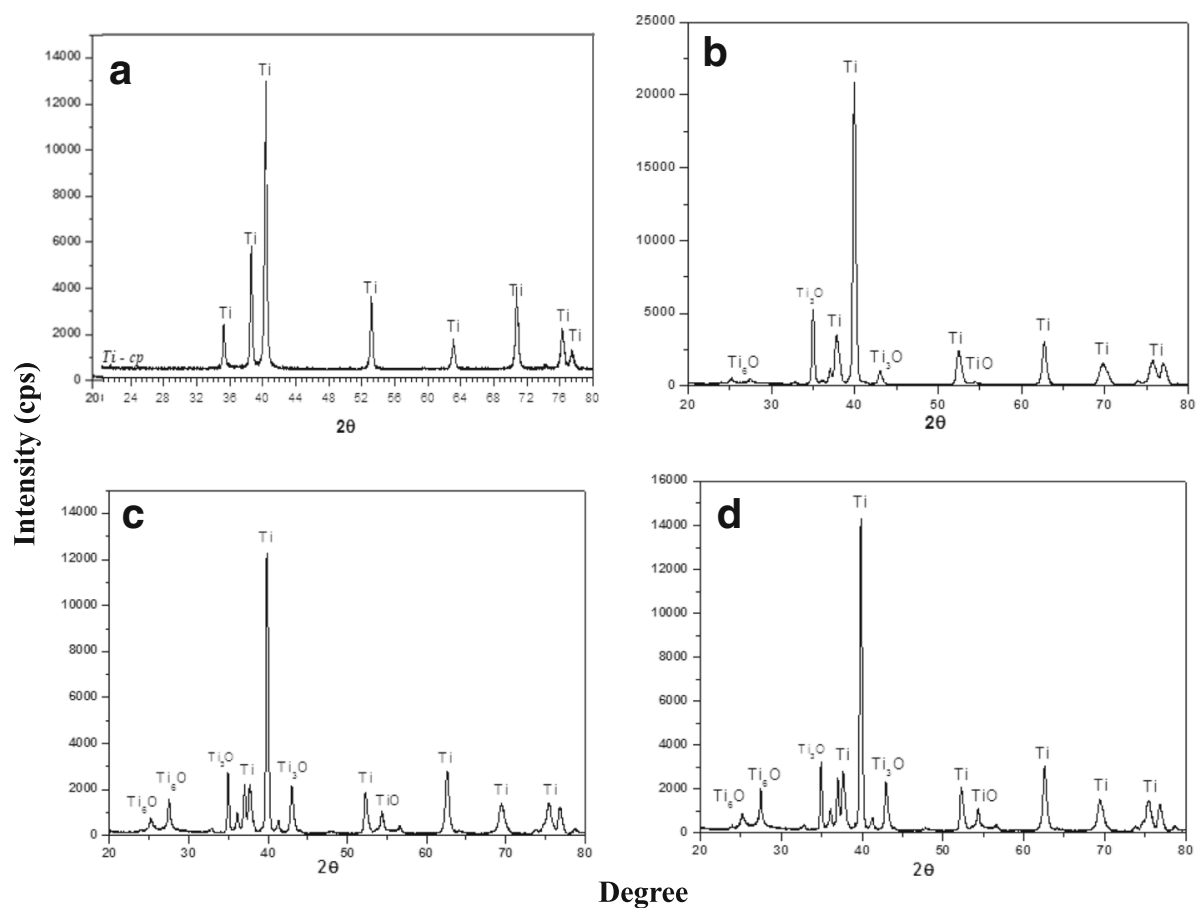

Fig. 2 X-ray diffraction spectra of Ti control (a), laser-processed titanium (LPT) produced using laser radiation at $132 \mathrm{~J} / \mathrm{cm}^{2}$ fluence (b), LPT produced using laser radiation at $210 \mathrm{~J} / \mathrm{cm}^{2}$ fluence (c), and LPT produced using laser radiation at $235 \mathrm{~J} / \mathrm{cm}^{2}$ fluence (d). cps counts per second, Ti titanium

The hUC-MSCs had a slower proliferation rate, and the Ti control surface produced the best results after 7 days $(\mathrm{OD}=0.243$ for $\mathrm{LPT}$ versus $\mathrm{OD}=0.733$ for the $\mathrm{Ti}$ control, $p<0.05)$. SEM analysis revealed cells showed the same behavior observed at MTT assay (Fig. $4 \mathrm{a}-\mathrm{c}$ ). The Ti control surface was uniformly covered and cells reached confluence, while the LPT surface cells did not reach confluence.

LPT induced osteogenic differentiation in the hUC-MSCs ALP activity increased in the hUC-MSCs cultured on the LPT in BM. A peak in activity was observed after 3 days
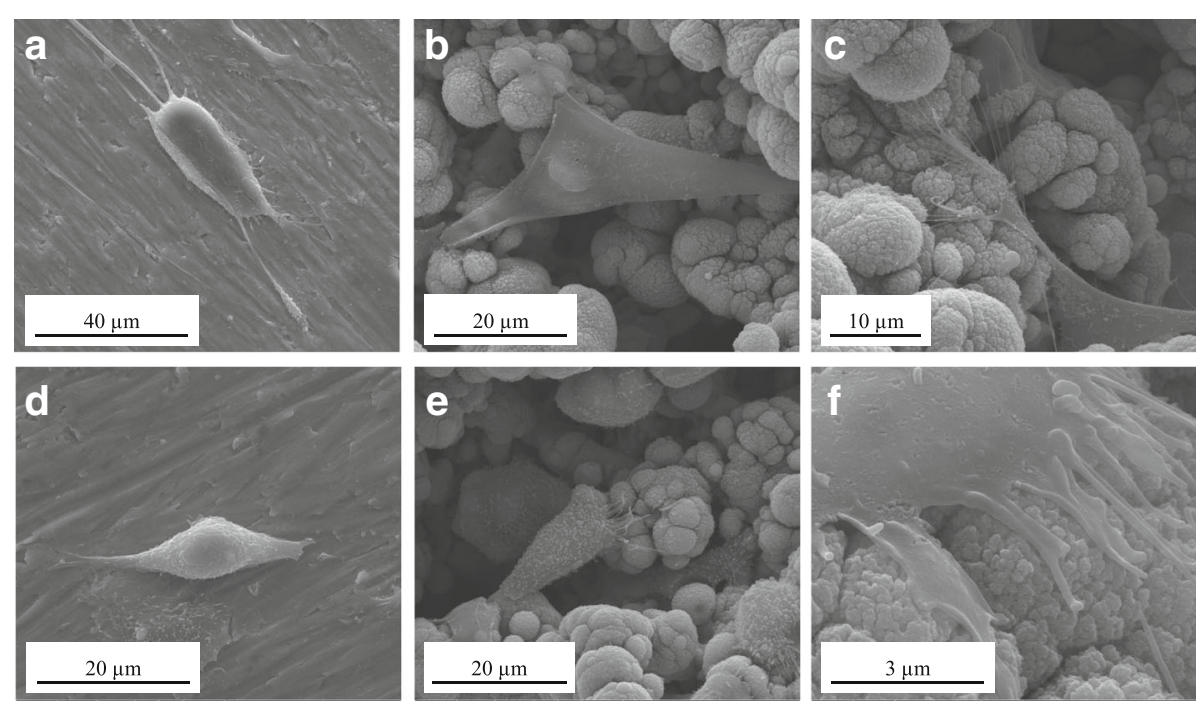

Fig. 3 Scanning electron microscopy micrographs of hUC-MSCs cultured after $24 \mathrm{~h}$ on Ti control (a) and laser-processed titanium (LPT) produced using laser radiation at $235 \mathrm{~J} / \mathrm{cm}^{2}$ fluence $(\mathbf{b}$, c); surfaces at $\times 3000, \times 5000$, and $\times 7000$ magnification. CHO-k1 cells after $24 \mathrm{~h}$ of culture on Ti control (d) and LPT produced using laser radiation at $235 \mathrm{~J} / \mathrm{cm}^{2}$ fluence $(\mathbf{e}, \mathbf{f})$. Surfaces at $\times 6000, \times 5000$, and $\times 40,000$ magnification 

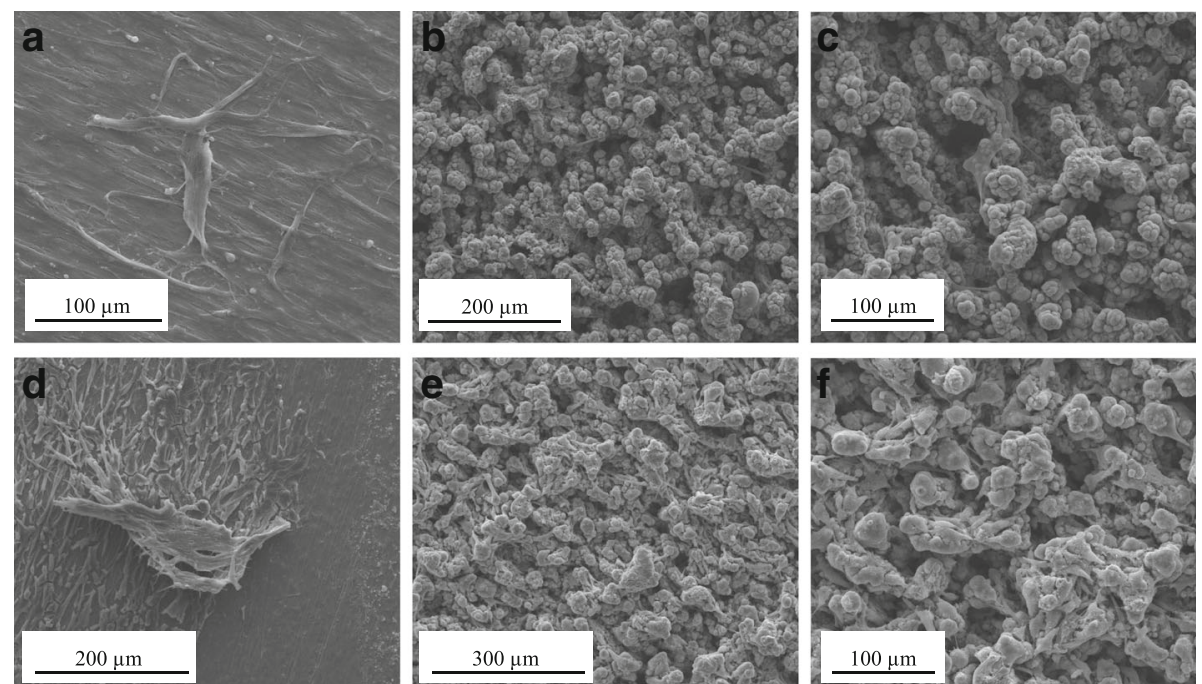

Fig. 4 Scanning electron microscopy micrographs after culture for 7 days. hUC-MSCS on Ti control (a) and laser-processed titanium (LPT) (b, c) surfaces. CHO-k1 cells on Ti control (d) and LPT (e, f) surfaces. a x1000, b ×500, c ×800, d ×600, e ×400, f $\times 800$

$(\mathrm{OD}=174.01 \pm 17.45$ for $\mathrm{LPT}$ versus $\mathrm{OD}=88.67 \pm 0.464$ for the Ti control, $p<0.01$ ) (Fig. 6a). Curiously, the peak in ALP activity occurred at a later time (i.e., after 7 days) when the cells were maintained in medium with osteogenic inducers (Fig. 6b). Furthermore, the LPT surfaces seem to have promoted the enhancement of extracellular matrix mineralization in the hUC-MSCs after 7 days in $\mathrm{BM}(\mathrm{OD}=0.1983 \pm 0.079$ for $\mathrm{LPT}$ versus $\mathrm{OD}=0.1425 \pm$ 0.069 for the Ti control), and this effect was even more pronounced (i.e., 3.6 times higher) in the presence of osteogenic inducers $(\mathrm{OD}=0.3634 \pm 0.060$ for $\mathrm{LPT}$ versus

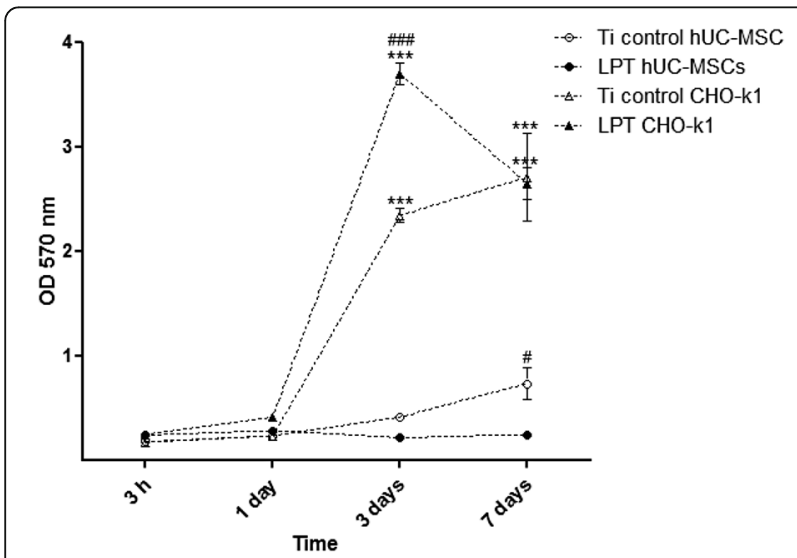

Fig. 5 MTT cell metabolic activity assay. hUC-MSC and CHO-k1 cell adhesion and proliferation results on the two different types of titanium discs (laser-processed titanium (LPT) and Ti control) at different times ( $3 \mathrm{~h}$, and 1,3 , and 7 days). ${ }^{* * *}$ Statistically significant differences between cell types at $p<0.001$; \#\#\# represents statistically significant differences between Ti surfaces $p<0.001$. Data represent means of three independent experiments and SD. MTT, 3-(4,5-dimethylthiazol-2-yl)2,5-diphenyltetrazolium bromide, OD optical density
$\mathrm{OD}=0.0991 \pm 0.020$ for the Ti control) (Fig. 7a, b). After 14 days, the difference between the Ti discs was significant $(p<0.01)$ when the cells were incubated in OM (Fig. 7b).

We also investigated osteogenic differentiation by analyzing gene expression to verify the osteoinductive properties of LPT. The canonical osteogenic markers alkaline phosphatase (ALPL), run-related transcription factor 2 (RUNX2), bone morphogenetic protein 2 (BMP2), osteocalcin $(\mathrm{OCN})$, and osteopontin $(\mathrm{OPN})$ were examined over time (7 and 14 days), using GAPDH as a housekeeping gene. Gene expression fold change, reported in this work, using Ti control as negative control, showed an increase expression of $A L P L, R U N X 2, O C N, B M P 2$, and $O P N$ in LPT after 7 days in BM. However, in the presence of OM this increase was not observed. In fact, significant differences in the fold changes were observed when cells cultured in BM were compared with those on OM for $A L P L, O C N$, and $O P N(p<0.05)$ (Fig. 8). No differences in the osteogenic markers expression were observed between cells cultured in BM and OM after 14 days of culture (data not shown).

\section{Discussion}

In recent years, many studies have investigated the influence of the physical and chemical surface characteristics of materials on the biological cascade of events leading to the osteointegration of implants. Many authors agree that the biocompatibility of titanium (Ti) implants depends on the properties of the oxide layer on the surface. Lavisse et al. [18] studied the formation of oxide layers on Ti during laser ablation, and demonstrated the formation of $\mathrm{Ti}_{6} \mathrm{O}, \mathrm{Ti}_{2} \mathrm{O}$, and $\mathrm{Ti}_{3} \mathrm{O}$. Several studies have also shown that the formation of an oxide layer 


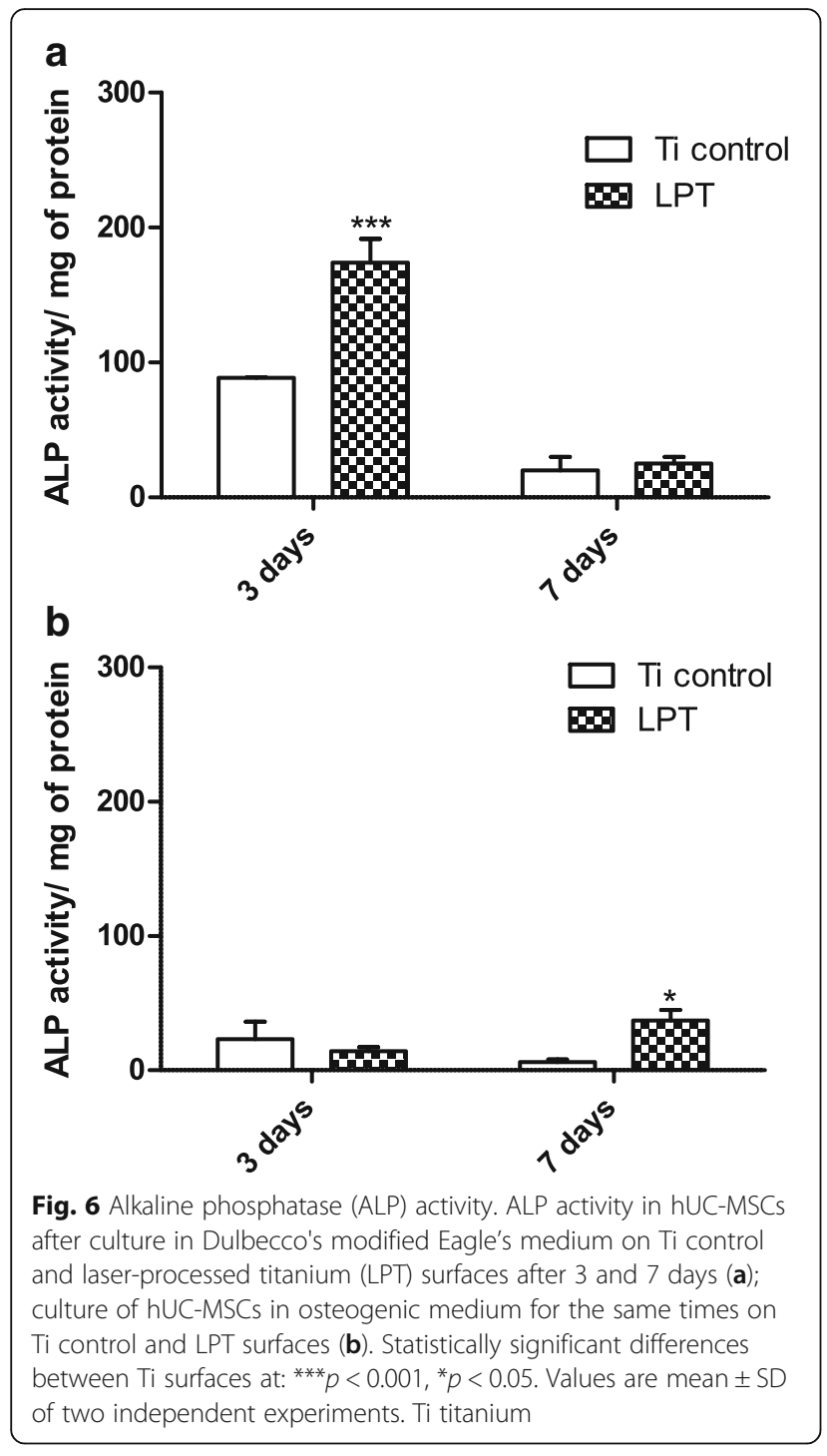

improves cell growth on the surface of $\mathrm{Ti}[9,11,19-21]$, which makes micro-texturing by laser beam (Yb-YAG) an excellent technique for bone medicine.

In the present study, we confirmed the formation of an oxide layer on LPT surfaces (Table 1). Titanium and oxygen were the most common elements found (Fig. 2). No other elements were found on the laser-treated surfaces, revealing a high degree of purity, and showing this process to be without contamination. In agreement with a study by Braga et al. [22], our results showed that the oxidation state of the metallic $\mathrm{Ti}$ increased as the fluence of the laser radiation increased; there was a higher degree of oxide layer formation on the Ti surface produced at a laser fluence of $235 \mathrm{~J} / \mathrm{cm}^{2}$. Biomaterial surfaces interact with water, ions, and numerous biomolecules after implantation. These interactions include hydroxylation of the oxide surface, electrical double-layer formation, protein adsorption,

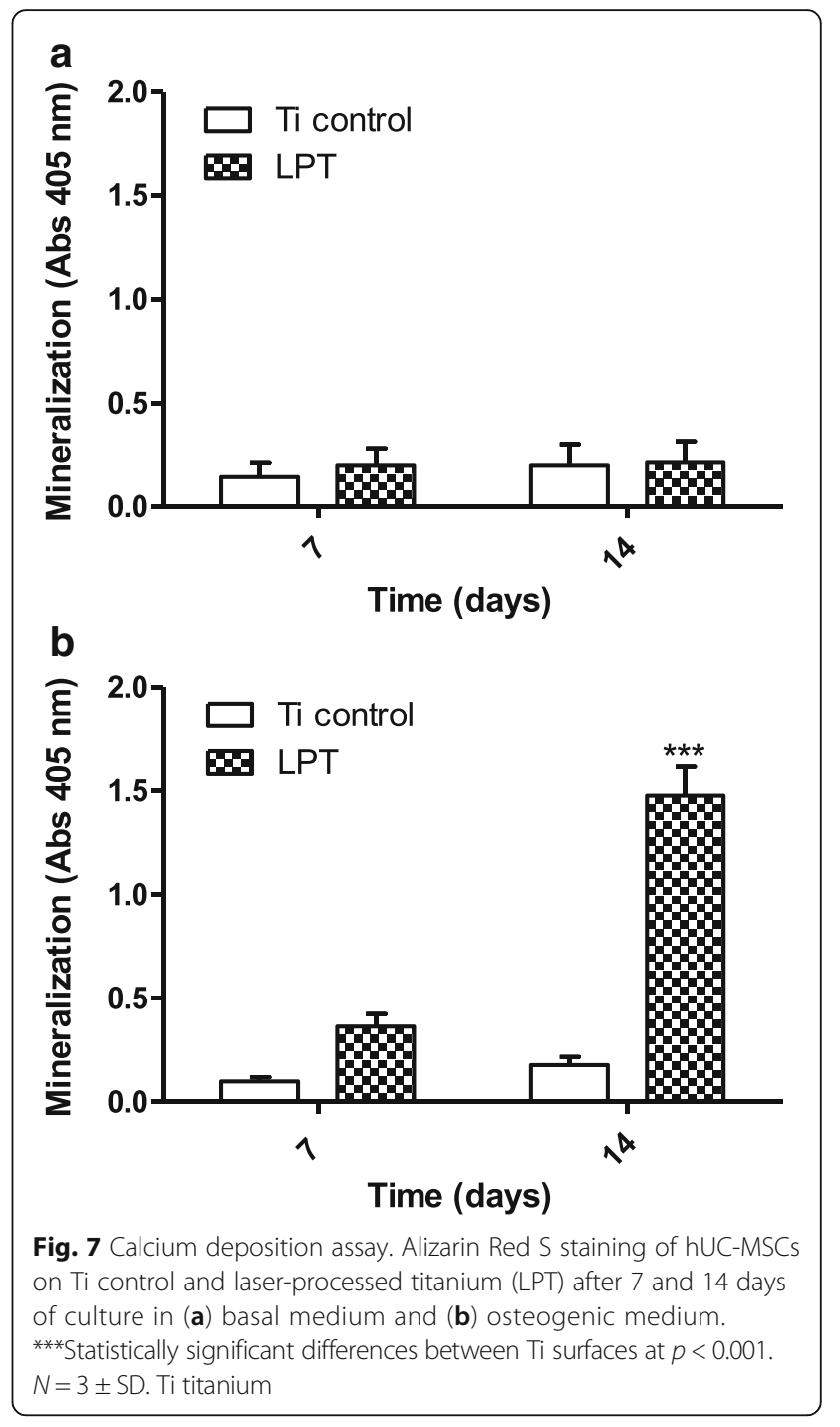

and denaturation, determining how cells and tissues respond to the implant [23].

The topographical analysis of the LPT surfaces showed a complex morphology with micro and nano-scaled patterns. As described by Sisti et al. [4], laser-modified Ti surfaces have distinct topographies with a "cauliflower" morphology that provides a larger surface area and enhanced wettability [4]. Several studies have demonstrated the influence of porous surfaces on cell adhesion [23-26], and our results (Fig. 5c) showed that the cells on the lasertreated $\mathrm{Ti}$ surfaces developed numerous filopodia. This confirms that cells on porous surfaces can modify their morphology to follow the surface topography of the sample.

Cell attachment and growth are primarily associated with the chemistry of the material and its surface characteristics. Because cell culture media and body fluids are water based, the wettability of the implant affects the attachment of cells to its surface [27]. The results 


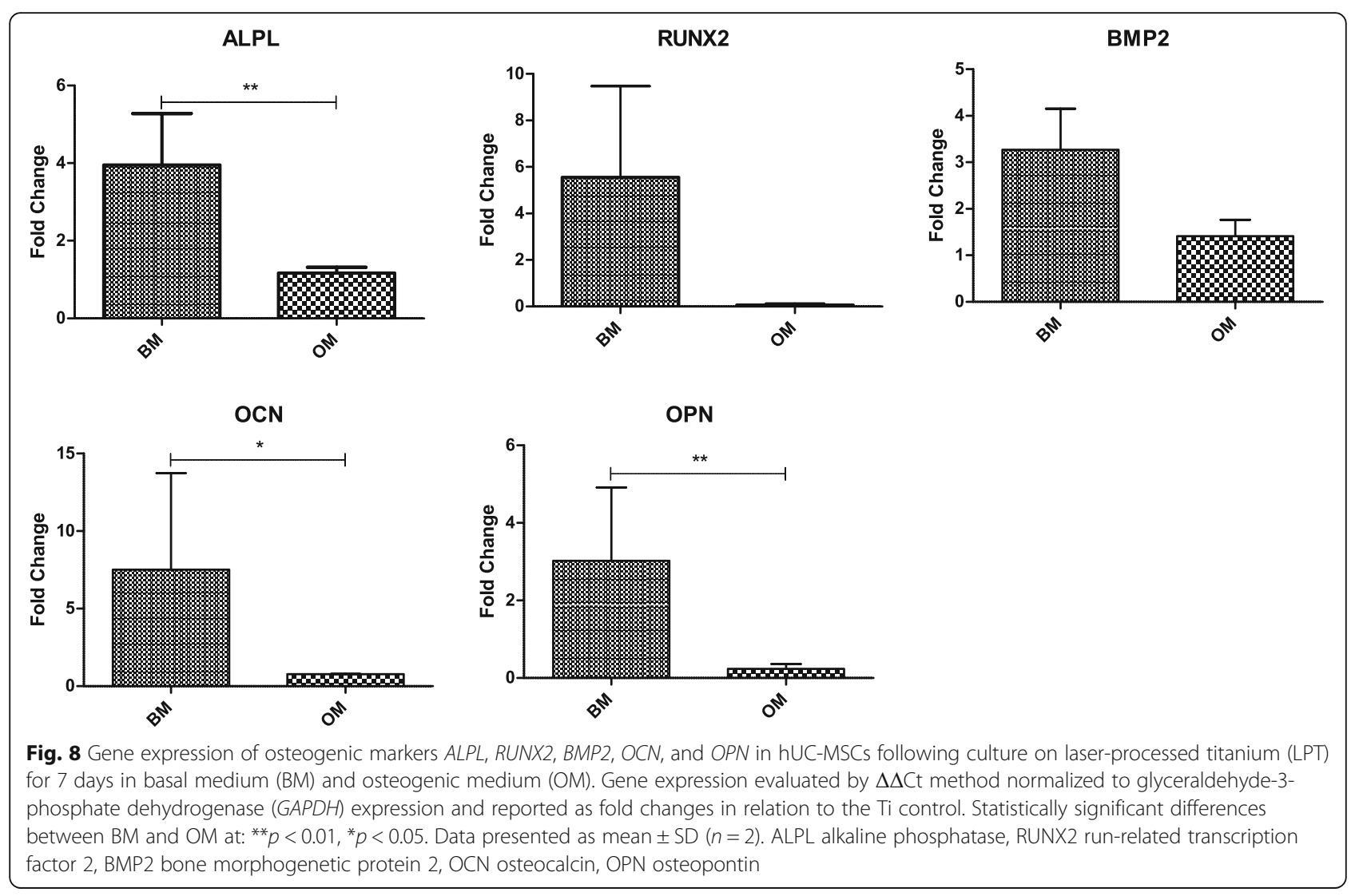

presented in Table 2 show an improvement in hydrophilicity of the two laser-treated surfaces compared with the Ti controls. Balla et al. [7] concluded that cellular attachment will be poor on any hydrophobic surface with a high contact angle; therefore, we did not culture hUC-MSCs on the Ti surfaces that had been treated by laser ablation at $210 \mathrm{~J} / \mathrm{cm}^{2}$ fluence because they had unsuitable wettability (the contact angle was higher than $90^{\circ}$ ). Moreover, low contact angles mean high surface energy, which is another factor that can contribute to better cell attachment [28].

Based on the preliminary studies, the parameters chosen to select the surface used in the experiments with hUC-MSCs were the presence of oxides on the $\mathrm{Ti}$ surface and the surface energy. These parameters enabled us to determine the most appropriate $\mathrm{Ti}$ surface for our in-vitro studies, which was the surface that had undergone laser ablation at $235 \mathrm{~J} / \mathrm{cm}^{2}$ fluence.

We used hUC-MSCs and CHO-K1 cells to evaluate the in-vitro biocompatibility of the laser-treated $\mathrm{Ti}$ (235 $\mathrm{J} / \mathrm{cm}^{2}$ fluence). As expected, our experimental data indicated that the $\mathrm{CHO}-\mathrm{k} 1$ cells grew better on the LPT surfaces over 7 days (Fig. 5). In our previous work [16], we showed that $\mathrm{CHO}-\mathrm{k} 1$ cells adhere more readily to rough $\mathrm{Ti}$ surfaces owing to their greater hydrophilicity. We observed different behavior in the hUC-MSCs over
7 days on the LPT surface. The hUC-MSCs had a lower proliferation rate and better results on the $\mathrm{Ti}$ control surface (Fig. 5). The cells did not reach confluence and were distributed in multiple layers inside the porous surface (Fig. 4b, c). Some authors have reported reduced proliferation in cells with osteogenic lineage on rough $\mathrm{Ti}$ surfaces compared with on smooth surfaces $[6,29-31]$. Therefore, the differences observed in the MTT assay for CHO-k1 cells and hUC-MSCs (Fig. 5) could be related to cell-dependent responses to surface modification. The LPT surface could reduce the proliferation of hUC-MSCs and increase osteogenic differentiation.

hUC-MSCs provide a reproducible cell culture model of osteogenesis, and their in-vitro behavior reflects the influence of surface topography in vivo [32]. The oxide layer, for example, may interact well with nano-scaled proteins, and may also induce hUC-MSCs to differentiate into the osteogenic lineage in vivo [19]. Therefore, we investigated ALP activity as an early osteogenic differentiation marker, and matrix mineralization as a late marker, to evaluate the osteogenic potential of the LPT surface (235 $\mathrm{J} / \mathrm{cm}^{2}$ fluence).

Our data showed that the ALP activity of the hUCMSCs on the LPT surface was improved in comparison with those on the $\mathrm{Ti}$ control and culture plate (data not shown), even without the addition of an osteogenic 
inducer. The highest ALP activity occurred after 3 days of culture on the LPT surface (Fig. 6a), but the extracellular mineralization values were similar for both surfaces (Fig. 7a). This behavior was also observed by Fadeeva et al. [33]. However, in the presence of osteogenic inducers, we observed the opposite results for ALP activity and extracellular mineralization (Figs. 6b and 7b). Similar findings for ALP activity, with and without osteogenic inducers, were reported by Sisti et al. [4] after 10 days of culture when no differences in ALP activity in osteogenic medium $(\mathrm{OM})$ was found between laser and machined Ti surfaces. Fadeeva et al. [33] also did not observe ALP activity differences between rough and smooth surfaces in OM. After 7 and 14 days, mouse calvarial osteoblasts seeded on $\mathrm{Ti}$ discs presented ALP activity enhanced threefold in cells cultured on rough surfaces compared with osteoblasts cultured on smooth surfaces in $\mathrm{OM}[8]$.

There is no consensus in the literature over the effect of rough Ti on ALP activity, mainly due to several variables such as cell type, growth time, and growing conditions. A rough surface has been reported to increase in basal medium (BM) [34] or to not affect in OM [35] the activity of ALP. This shows the importance of this kind of research to improve knowledge in this field.

The discrepancies observed in this work can be attributed to a synergic effect between osteogenic inducers and surface topography stimuli that affects the peak of ALP activity and therefore the differentiation process. In $\mathrm{BM}$, the LPT surface was able to initiate osteoinduction per se, but it occurred later than in the presence of OM.

We determined the expression levels of five osteogenic markers (ALPL, RUNX2, BMP2, OCN, and OPN) to evaluate the responses of hUC-MSCs exposed to an LPT surface at the molecular level. ALPL and RUNX2 are commonly expressed in the early stages of osteogenesis [36]. Our results revealed increased expression of these genes at day 7 in $\mathrm{BM}$ and decreased expression at day 14. As described by Sisti et al. [4], RUNX2 is essential for osteoblast maturation; it is a key regulator of OCN and ALPL. OCN and OPN are noncollagenous bone proteins, and are involved in matrix mineralization [35]. The phosphorylated glycoprotein OPN is thought to be present in the early stages of osteogenesis, promoting the attachment of osteoblasts to the extracellular matrix, and it is actively involved in the resorption of bone [4,36-38]. During the remodeling process, osteoblastic bone formation is associated with osteoclastic bone resorption [36]. Therefore, the surface of the implanted material should be conducive to osteoblast and osteoclast activity [39]. In the present study, the expression levels of both $O C N$ and $O P N$ were upregulated at 7 days, although we observed an $O C N$ peak at 14 days. This upregulation at the mRNA level at day 7 in BM could indicate the induction of
hUC-MSC differentiation into osteoblasts following laser beam irradiation.

Perrotti et al. [36] and Jiang et al. [40] also observed a gene expression increase in cells growth on $\mathrm{Ti}$ rough surfaces in the absence of osteogenic inductors. Titanium treated with acid and hydrogen peroxide (TiAcidHP) showed an increase expression of osteogenic markers when compared with Ti control in BM. However, this difference was not evident in OM [40]. Gardin et al. [37] also showed an increase on expression of osteoblast markers in human adipose-derived stem cells seeded onto Ti rough surfaces in BM. Similar results were obtained when those cells were seeded on tissue culture plates in the presence of OM. Our gene expression data showed an increase of osteogenic markers in cells cultured in BM on LPT, when compared with Ti control; nevertheless, cells cultured in $\mathrm{OM}$ on the untreated surfaces also followed the differentiation pathway due to the presence of inductors in the medium, attenuating the effect of surface topology and resulting in a lower value of fold change. Similar behavior was observed by Wang et al. [35] when no differences in gene expression were observed on rough surfaces in OM.

Our results show that hUC-MSCs cultured on laserirradiated $\mathrm{Ti}$ express osteogenic markers and display ALP activity at an early stage. The main finding of the present study is the osteogenic potential of the material surface itself, which mimics the natural environment of the bone-titanium interface in vivo. ALP activity and osteogenic marker expression were promoted earlier on the LPT, even in early-stage hUC-MSCs, and were less closely associated with an osteogenic lineage.

\section{Conclusions}

Taken together, our results suggest that commercially available pure titanium discs which have been irradiated with a laser beam (Yb-YAG) at $235 \mathrm{~J} / \mathrm{cm}^{2}$ fluence modulate cellular behavior in a manner that is dependent on the cell type. This clean and reproducible process produces a complex surface topography with micro and nano-scaled patterns, and stoichiometric and nonstoichiometric oxides that improve the hydrophilicity of the LPT surface. Despite low hUC-MSC proliferation, the LPT surface seems to stimulate osteogenic differentiation, leading to an increase in mineralization. This translates into better osseointegration, and demonstrates the potential of a hybrid hUCMSC-LPT for prosthetic bone devices; its use in regenerative medicine could promote better outcomes.

\section{Abbreviations}

ALP: Alkaline phosphatase; BM: Basal medium; BMP2: Bone morphogenetic protein 2; CHO-k1: Chinese hamster ovary cells; CPDS: Committee for Powder Diffraction Studies; DMEM: Dulbecco's modified Eagle's medium; FBS: Fetal bovine serum; GAPDH: Glyceraldehyde-3-phosphate dehydrogenase; hBM-MSC: Human bone marrow mesenchymal stem cell; hMSC: Human mesenchymal stem cell; hUC-MSC: Human umbilical cord mesenchymal stem cell; LPT: Laser-processed titanium; MTT: 3-(4,5-Dimethylthiazol-2-yl)-2,5- 
diphenyltetrazolium bromide; OCN: Osteocalcin; OM: Osteogenic medium; OPN: Osteopontin; qRT-PCR: Quantitative real-time polymerase chain reaction; RUNX2: Run-related transcription factor 2; SEM: Scanning electron microscopy; Ti: Titanium; XRD: X-ray diffraction

\section{Acknowledgements}

The authors acknowledge CETENE (Centro de Tecnologias Estratégicas do Nordeste, Ministério da Ciência Tecnologia e Informação, Brazil) for carrying out SEM on the hUC-MSCS and CHO-k1 cells cultured on different titanium surfaces.

\section{Funding}

This work received financial support from Conselho Nacional de Desenvolvimento Científico e Tecnológico (CNPq process n. 404762/2012-3), from INCT in Regenerative Medicine (CNPq process n. 465656/2014-5), and from Coordenação de Aperfeiçoamento de Pessoal de Nível Superior (CAPES, process n. 23038.008617/2010-21).

\section{Availability of data and materials}

All data generated or analyzed during this study are included in this published article.

\section{Authors' contributions}

TABB, JDFdQ, JTdF, and EAF developed the experimental assays and data analysis. SRBdM, ACG, SMGM, JDFdQ, and TABB conceived the study, participated in its design and data analysis, and helped to draft the manuscript. All authors read and approved the final manuscript.

\section{Ethics approval and consent to participate}

This work was submitted to and approved by the Ethics Committee of the Federal University of Rio Grande do Norte (FR132464). Umbilical cord specimens were obtained after written informed consent was signed by mothers.

\section{Consent for publication}

Not applicable.

\section{Competing interests}

The authors declare that they have no competing interests.

\section{Publisher's Note}

Springer Nature remains neutral with regard to jurisdictional claims in published maps and institutional affiliations.

\section{Author details}

'Departamento de Biologia Celular e Genética, CB-UFRN, Universidade Federal do Rio Grande do Norte, Campus Universitário, Lagoa Nova, 59072-970 Natal, RN, Brazil. Departamento de Físico-Química, Instituto de Química de Araraquara-UNESP, Araraquara, SP, Brazil. ${ }^{3}$ Programa de Pós Graduação em Ciências da Saúde, Natal, RN, Brazil.

Received: 2 May 2017 Revised: 13 September 2017 Accepted: 30 October 2017 Published online: 28 November 2017

\section{References}

1. Geetha M, Singh AK, Asokamani R, Gogia AK. Ti based biomaterials, the ultimate choice for orthopaedic implants-a review. Prog Mater Sci. 2009;54:397-425. doi: 10.1016/j.pmatsci.2008.06.004.

2. Jacchetti E, Di Rienzo C, Meucci S, Nocchi F, Beltram F, Cecchini M. Wharton's Jelly human mesenchymal stem cell contact guidance by noisy nanotopographies. Sci Rep. 2014;4:3830. doi: 10.1038/srep03830.

3. Schiavi J, Keller L, Morand D-N, De Isla N, Huck O, Lutz JC, et al. Active implant combining human stem cell microtissues and growth factors for bone-regenerative nanomedicine. Nanomedicine. 2015;10:753-63. doi: 10.2217/nnm.14.228.

4. Sisti KE, de Andrés MC, Johnston D, Almeida-Filho E, Guastaldi AC, Oreffo ROC. Skeletal stem cell and bone implant interactions are enhanced by LASER titanium modification. Biochem Biophys Res Commun. 2016;473:719-25. doi: 10.1016/j.bbrc.2015.10.013.
5. Novin M, Faghihi S. Mouse bone marrow-derived mesenchymal stem cell response to nanostructured titanium substrates produced by high-pressure torsion. Surf Interface Anal. 2013;45:619-27. doi: 10.1002/sia.5101.

6. Verrier S, Peroglio M, Voisard C, Lechmann B, Alini M. The osteogenic differentiation of human osteoprogenitor cells on anodic-plasma-chemical treated Ti6Al7Nb. Biomaterials. 2011;32:672-80. doi: 10.1016/j.biomaterials. 2010.09.028

7. Balla VK, Bhat A, Bose S, Bandyopadhyay A. Laser processed TiN reinforced Ti6Al4V composite coatings. J Mech Behav Biomed Mater. 2012;6:9-20. doi: 10.1016/j.jmbbm.2011.09.007.

8. Mariscal-Muñoz E, Costa CAS, Tavares HS, Bianchi J, Hebling J, Machado JPB, et al. Osteoblast differentiation is enhanced by a nano-to-micro hybrid titanium surface created by Yb:YAG laser irradiation. Clin Oral Investig. 2016; 20:503-11. doi: 10.1007/s00784-015-1533-1.

9. Queiroz TP, Souza FÁ, Guastaldi AC, Margonar R, Garcia-Júnior IR, HochuliVieira E. Commercially pure titanium implants with surfaces modified by laser beam with and without chemical deposition of apatite. Biomechanical and topographical analysis in rabbits. Clin Oral Implants Res. 2013;24:896-903. doi: 10.1111/j.1600-0501.2012.02471.x.

10. Stiehler M, Lind M, Mygind T, Baatrup A, Dolatshahi-Pirouz A, Li H, et al. Morphology, proliferation, and osteogenic differentiation of mesenchymal stem cells cultured on titanium, tantalum, and chromium surfaces. J Biomed Mater Res Part A. 2008;86A:448-58. doi: 10.1002/jbm.a.31602.

11. Annunziata M, Oliva A, Buosciolo A, Giordano M, Guida A, Guida L. Bone marrow mesenchymal stem cell response to nano-structured oxidized and turned titanium surfaces. Clin Oral Implants Res. 2012;23:733-40. doi: 10.1111/j.1600-0501.2011.02194.x.

12. Wang H-S, Hung S-C, Peng S-T, Huang C-C, Wei H-M, Guo Y-J, et al. Mesenchymal stem cells in the Wharton's jelly of the human umbilical cord. Stem Cells. 2004;22:1330-7. doi: 10.1634/stemcells.2004-0013.

13. Kwon A, Kim Y, Kim M, Kim J, Choi H, Jekarl DW, et al. Tissue-specific differentiation potency of mesenchymal stromal cells from perinatal tissues. Sci Rep. 2016;6:23544. doi: 10.1038/srep23544.

14. Rietveld HM. A profile refinement method for nuclear and magnetic structures. J Appl Crystallogr. 1969;2:65-71. doi: 10.1107/S0021889869006558.

15. Cornélio DA, Tavares JCM, Pimentel TVCDA, Cavalcanti GB, Batistuzzo de Medeiros SR. Cytokinesis-block micronucleus assay adapted for analyzing genomic instability of human mesenchymal stem cells. Stem Cells Dev. 2014;23:823-38. doi: 10.1089/scd.2013.0383.

16. de Queiroz JDF, Leal AM de S, Terada M, Agnez-Lima LF, Costa I, Pinto NC de $S$, et al. Surface modification by argon plasma treatment improves antioxidant defense ability of $\mathrm{CHO}-\mathrm{k} 1$ cells on titanium surfaces. Toxicol Vitr. 2014;28:381-7. doi: 10.1016/j.tiv.2013.11.012.

17. Jääger K, Islam S, Zajac P, Linnarsson S, Neuman T. RNA-seq analysis reveals different dynamics of differentiation of human dermis- and adipose-derived stromal stem cells. PLoS One. 2012;7:1-9. doi: 10.1371/journal.pone.0038833.

18. Lavisse L, Sahour MC, Jouvard JM, Pillon G, Marco de Lucas MC, Bourgeois $\mathrm{S}$, et al. Growth of titanium oxynitride layers by short pulsed Nd:YAG laser treatment of Ti plates: influence of the cumulated laser fluence. Appl Surf Sci. 2009;255:5515-8. doi: 10.1016/j.apsusc.2008.07.197.

19. Chiang C-Y, Chiou S-H, Yang W-E, Hsu M-L, Yung M-C, Tsai M-L, et al. Formation of TiO2 nano-network on titanium surface increases the human cell growth. Dent Mater. 2009;25:1022-9. doi: 10.1016/..dental.2009.03.001.

20. Rapuano $B E$, MacDonald DE. Surface oxide net charge of a titanium alloy: modulation of fibronectin-activated attachment and spreading of osteogenic cells. Colloids Surfaces B Biointerfaces. 2011;82:95-103. doi: 10.1016/j.colsurfb.2010.08.023.

21. Ishizaki K, Sugita Y, Iwasa F, Minamikawa H, Ueno T, Yamada M, Suzuki T, Ogawa T. Nanometer-thin $\mathrm{TiO} 2$ enhances skeletal muscle cell phenotype and behavior. Int J Nanomed. 2011;6:2191-3. doi: 10.2147/IJN.S24839..

22. Braga FJC, Marques RFC, Filho E de A, Guastaldi AC. Surface modification of Ti dental implants by Nd:YVO4 laser irradiation. Appl Surf Sci. 2007;253: 9203-8. doi: 10.1016/j.apsusc.2007.05.048.

23. Puleo DA, Thomas MV. Implant surfaces. Dent Clin North Am. 2006;50:323-38. doi: 10.1016/j.cden.2006.03.001.

24. Xue W, Krishna BV, Bandyopadhyay A, Bose S. Processing and biocompatibility evaluation of laser processed porous titanium. Acta Biomater. 2007:3:1007-18. doi: 10.1016/j.actbio.2007.05.009.

25. Rao PJ, Pelletier MH, Walsh WR, Mobbs RJ. Spine interbody implants: material selection and modification, functionalization and bioactivation of surfaces to improve osseointegration. Orthop Surg. 2014;6:81-9. doi: 10.1111/os.12098. 
26. Xu J, Weng X-J, Wang X, Huang J-Z, Zhang C, Muhammad H, et al. Potential use of porous titanium-niobium alloy in orthopedic implants: preparation and experimental study of its biocompatibility in vitro. PLoS One. 2013;8: e79289. doi: 10.1371/journal.pone.0079289.

27. Eriksson C, Nygren H, Ohlson K. Implantation of hydrophilic and hydrophobic titanium discs in rat tibia: cellular reactions on the surfaces during the first 3 weeks in bone. Biomaterials. 2004;25:4759-66. doi: 10.1016/j.biomaterials.2003.12.006.

28. Bodhak S, Bose S, Bandyopadhyay A. Role of surface charge and wettability on early stage mineralization and bone cell-materials interactions of polarized hydroxyapatite. Acta Biomater. 2009;5:2178-88. doi: 10.1016/j. actbio.2009.02.023.

29. Despang F, Bernhardt A, Lode A, Hanke T, Handtrack D, Kieback B, et al. Response of human bone marrow stromal cells to a novel ultra-fine-grained and dispersion-strengthened titanium-based material. Acta Biomater. 2010;6:1006-13. doi: 10.1016/j.actbio.2009.09.026.

30. Klinger A, Tadir A, Halabi A, Shapira L. The effect of surface processing of titanium implants on the behavior of human osteoblast-like Saos-2 cells. Clin Implant Dent Relat Res. 2011;13:64-70. doi: 10.1111/j.1708-8208.2009.00177.x.

31. Setzer B, Bächle M, Metzger MC, Kohal RJ. The gene-expression and phenotypic response of hFOB 1.19 osteoblasts to surface-modified titanium and zirconia. Biomaterials. 2009;30:979-90. doi: 10.1016/j.biomaterials.2008.10.054.

32. Mendonça DBS, Miguez PA, Mendonça G, Yamauchi M, Aragão FJL, Cooper LF. Titanium surface topography affects collagen biosynthesis of adherent cells. Bone. 2011;49:463-72. doi: 10.1016/j.bone.2011.04.019.

33. Fadeeva E, Deiwick A, Chichkov B, Schlie-Wolter S. Enhanced bioactivity of titanium by laser-generated lotus-topographies: molecular insights in osteogenic signaling pathways of hASCs. J Nanomed Nanotechnol. 2016; 7(5):1-9. doi: 10.4172/2157-7439.1000403..

34. Oughlis S, Lessim S, Changotade S, Poirier F, Bollotte F, Peltzer J, et al. The osteogenic differentiation improvement of human mesenchymal stem cells on titanium grafted with polyNaSS bioactive polymer. J Biomed Mater Res Part A. 2013;101A:582-9. doi: 10.1002/jbm.a.34336.

35. Wang H, Zhao B, Liu C, Wang C, Tan X, Hu M. A comparison of biocompatibility of a titanium alloy fabricated by electron beam melting and selective laser melting. PLoS One. 2016;11:e0158513. doi: 10.1371/journal.pone.0158513.

36. Perrotti $V$, Palmieri A, Pellati A, Degidi M, Ricci L, Piattelli A, et al. Effect of titanium surface topographies on human bone marrow stem cells differentiation in vitro. Odontology. 2013;101:133-9. doi: 10.1007/s10266-012-0067-0.

37. Gardin C, Ferroni L, Bressan E, Calvo-Guirado JL, Degidi M, Piattelli A, et al. Adult stem cells properties in terms of commitment, aging and biological safety of grit-blasted and Acid-etched Ti dental implants surfaces. Int J Mol Cell Med. 2014;3:225-36.

38. Yamada S. Osteoclastic resorption of calcium phosphate ceramics with different hydroxyapatite/ $\beta$-tricalcium phosphate ratios. Biomaterials. 1997:18:1037-41. doi: 10.1016/S0142-9612(97)00036-7.

39. Klein MO, Bijelic A, Toyoshima T, Götz H, Von Koppenfels RL, Al-Nawas B, et al. Long-term response of osteogenic cells on micron and submicronscale-structured hydrophilic titanium surfaces: sequence of cell proliferation and cell differentiation. Clin Oral Implants Res. 2010;21:642-9. doi: 10.1111/j. 1600-0501.2009.01883.x.

40. Zhang W, Li Z, Huang Q, Xu L, Li J, Jin Y, Wang G, Liu X, Jiang X. Effects of a hybrid micro/nanorod topography-modified titanium implant on adhesion and osteogenic differentiation in rat bone marrow mesenchymal stem cells. Int J Nanomed. 2013;8:257-65. doi: 10.2147/IJN.S39357.

\section{Submit your next manuscript to BioMed Central and we will help you at every step:}

- We accept pre-submission inquiries

- Our selector tool helps you to find the most relevant journal

- We provide round the clock customer support

- Convenient online submission

- Thorough peer review

- Inclusion in PubMed and all major indexing services

- Maximum visibility for your research

Submit your manuscript at www.biomedcentral.com/submit
Biomed Central 